\title{
Is low / intermediate grade prostate cancer still a contraindication for renal transplant?
}

Andrew Vicens-Morton I, Hide Yamamoto 2, Oussama Elhage 2, Rhana Zakri ı, Rick Popert 2, Ben Challacombe 2, Paul Cathcart 2, Prokar Dasgupta 2, Jonathon Olsburgh I.

\section{Introduction}

Men with end stage renal disease (ESRD) may also be diagnosed with prostate cancer (PCa). Historically active prostate cancer has ruled out the possibility of being considered for a renal transplant. Patients with treated prostate cancer and undetectable PSA may be considered after appropriate waiting time post-treatment. Prostate cancer is now categorised into low, intermediate and high risk disease based on PSA and Gleason grade on prostate biopsy.

\begin{tabular}{|c|c|c|c|}
\hline & Low-risk & Intermediate-risk & High-risk \\
\hline Definition & $\begin{array}{l}\mathrm{PSA}<10 \mathrm{ng} / \mathrm{mL} \\
\text { and GS }<7 \\
\text { and CT1-2a }\end{array}$ & $\begin{array}{l}\text { PSA } 10-20 \mathrm{ng} / \mathrm{mL} \\
\text { or GS7 } \\
\text { or CT2b }\end{array}$ & $\begin{array}{l}\text { PSA }>20 \mathrm{ng} / \mathrm{mL} \\
\text { or GS }>7 \\
\text { or c CT2C }\end{array}$ \\
\hline & \multicolumn{3}{|c|}{ Localised } \\
\hline
\end{tabular}

PSA = prostate-specific antigen.

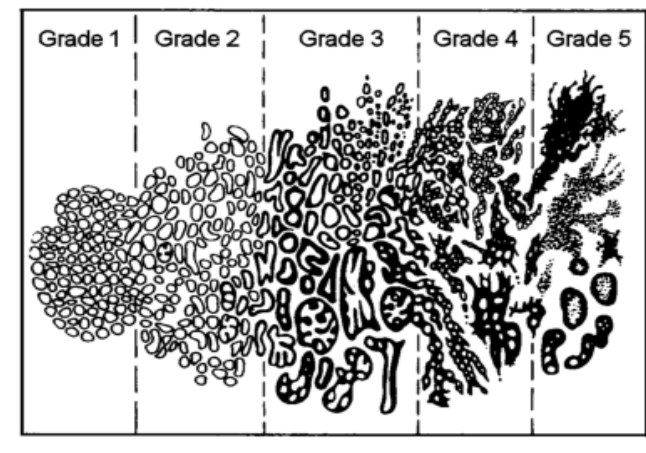

Fig. I. Gleason score description

Treatment options discussed with Low / intermediate PCa patients without ESRD are: active surveillance (AS), brachytherapy (BS) external beam radiotherapy (EBR) and radical prostatectomy (RP)
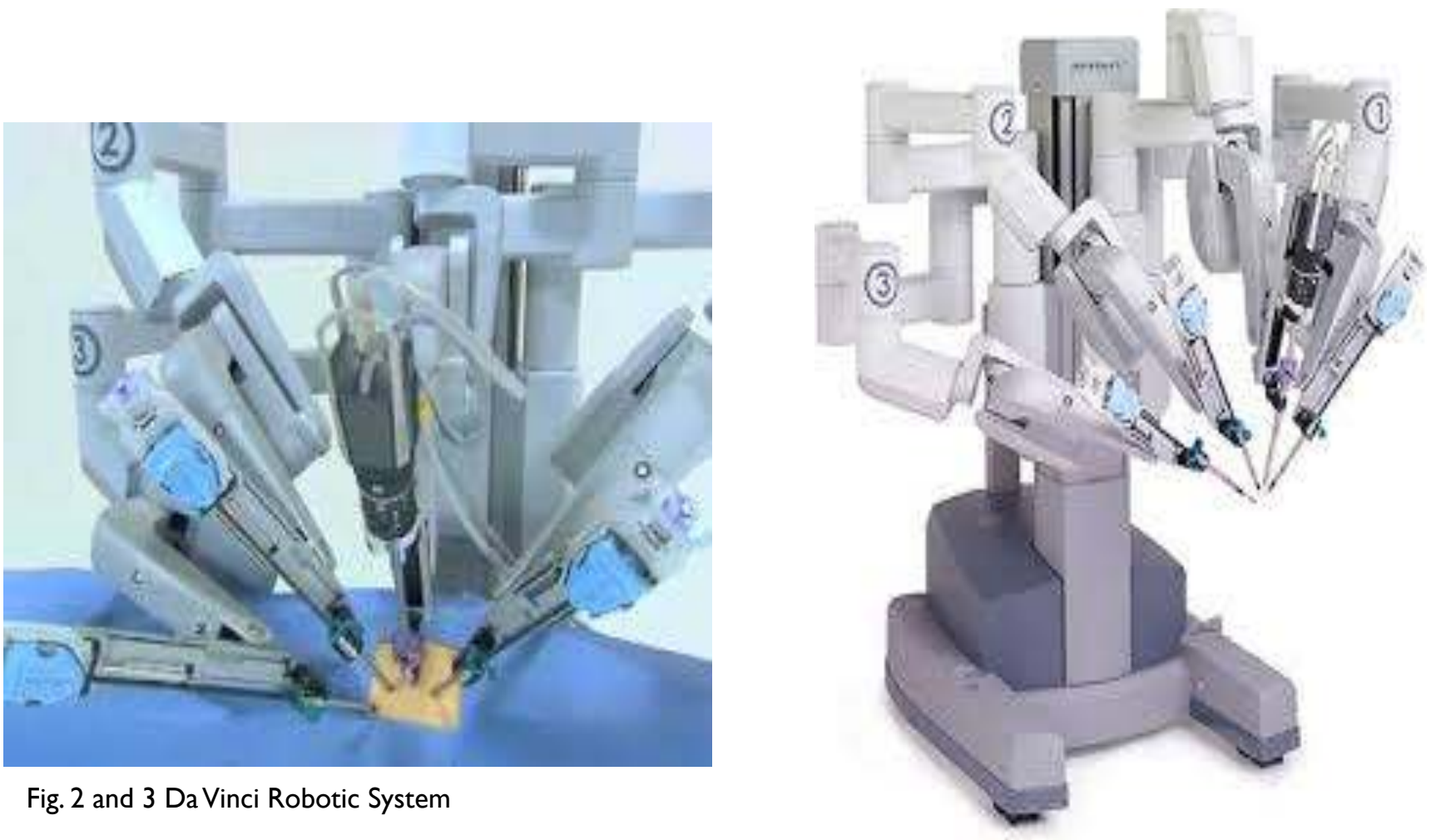

Fig. 2 and 3 Da Vinci Robotic System

\section{Objective}

Demonstrate our experience of managing patients with ESRD being considered for renal transplant (or re-transplantation) and low / intermediate grade $\mathrm{PCa}$.

\section{Methods}

A retrospective database of ESRD patients being considered for renal transplant and concomitant PCa was assessed for demographic details, PCa diagnosis and management, and ESRD management.

\section{Results}

During the last 12 years, I5 ESRD patients have been diagnosed with PCa as part of assessment for the transplant waiting list (RTxWL). One patient was found to have asymptomatic metastatic disease with a presenting PSA of $120 \mathrm{ng} / \mathrm{ml} .6$ were included in an AS protocol, 8 underwent robotic radical prostatectomy (RRP).
8 patients had RRP, Mean PSA 12.6 at Diagnosis; Biopsy Gleason $3+3$ in one case $3+4$ in two cases and $4+3$ in 5 cases; all have undetectable PSA after mean 46 months f/u; 2 received RTx both 6 years post RRP and both have stable good renal function; 2 patients are active on the RTxWL; 3 are awaiting activation on the RTXWL between 6-12 m post RRP and 1 is suspended for 3 years.

6 patients on the AS protocol, Mean PSA 6.7 at Diagnosis; Biopsy Gleason $3+3$ in four cases an $3+4$ in the remaining two; Mean Follow up 81 months. 2 patients are active on RTxWL on AS. 4 transplanted on AS. One was transplanted after 26 months on AS. He died of Oesophagus carcinoma with 93 months PCa progression-free follow-up (last PSA was 0.6). The second patient has stable renal function after 41 months $\mathrm{f} / \mathrm{u}$ and is due to have Prostatic MRI and template biopsy this year; the $3^{\text {rd }}$ had KTx on AS, the Tx failed and is currently back on Haemodialysis and does not wish to have a second transplant; regarding $\mathrm{PCa}$ he continues on AS. The $4^{\text {th }}$ patient had $\mathrm{PCa}$ progression after 2 years of AS; treated with Radiotherapy plus hormones, 5 years later he recieved a kidney transplant; currently he has stable renal function and his last PSA was 0.56 $\mathrm{ng} / \mathrm{ml}$.

\begin{tabular}{|c|c|c|c|c|c|c|c|}
\hline & $\begin{array}{c}\text { Treatment } \\
\text { protocol }\end{array}$ & Bx 1 Gleason 1 & Bx 1 Gleason 2 & $\begin{array}{c}\text { Presenting } \\
\text { PSA }\end{array}$ & $\begin{array}{c}\text { Current } \\
\text { PSA }\end{array}$ & $\begin{array}{l}\text { Kidney transplant } \\
\text { status }\end{array}$ & $\begin{array}{c}\mathrm{FN} \\
\text { (mths) }\end{array}$ \\
\hline 1 & AS & 3 & 3 & 14 & 16 & Active on Waiting list & 50 \\
\hline 2 & AS & 3 & 3 & 6,3 & 5,4 & Transplanted & 64 \\
\hline 3 & AS & 3 & 3 & 5,8 & 7 & Active on Waiting list & 45 \\
\hline 4 & AS & 3 & 3 & 0,6 & 0,6 & Transplanted & 157 \\
\hline 5 & AS & 3 & 4 & 5,82 & 4,15 & Transplanted & 43 \\
\hline 6 & AS & 3 & 4 & 7,65 & 0,56 & Transplanted & 128 \\
\hline 7 & RRP & 3 & 3 & 12,6 & $<0.03$ & Transplanted & 98 \\
\hline 8 & RRP & 4 & 3 & 13,7 & $<0.03$ & Awaiting activation & 7 \\
\hline 9 & RRP & 4 & 3 & 18,6 & $<0.03$ & Awaiting activation & 9 \\
\hline 10 & RRP & 3 & 4 & 10,3 & $<0.03$ & Transplanted & 74 \\
\hline 11 & RRP & 4 & 3 & 9,1 & $<0.03$ & $\begin{array}{l}\text { Awaliting second } \\
\text { transplant }\end{array}$ & 16 \\
\hline 12 & RRP & 3 & 4 & 6,8 & $<0.03$ & $\begin{array}{l}\text { Awalting second } \\
\text { transplant }\end{array}$ & 5 \\
\hline 13 & RRP & 4 & 3 & 19 & $<0.03$ & Awaiting activation & 7 \\
\hline 14 & RRP & 4 & 3 & 10,4 & $<0.03$ & $\begin{array}{c}\text { Suspended for } 3 \\
\text { years }\end{array}$ & 6 \\
\hline 15 & Hormones & 3 & 4 & $>100$ & $<0.03$ & Suspended & 4 \\
\hline
\end{tabular}

Table I. Description of the patients. (AS) active surveillance. (RRP) Robotic radical prostatectomy.

\section{Conclusion}

Even though our cohort is small, our experience suggests that ESRD patients should be offered the standard treatment options for low I intermediate risk $\mathrm{PCa}$ based on individual $\mathrm{PCa}$ disease characteristics and their RTx options (including whether a living or deceased kidney donor is available). AS in appropriate ESRD patients may no longer be a contra-indication to RTx. 